\title{
Influence of temperature and time on the
}

\section{$\mathrm{Eu}^{3+}$ reaction with synthetic Na-Mica-n (n=2}

\section{and 4)}

M. José García-Jiménez ${ }^{a}$, Agustín Cota ${ }^{b}$, Francisco J. Osuna ${ }^{c}$, Esperanza Pavón ${ }^{d}$ and María D. Albac,

${ }^{a}$ Instituto Investigaciones Químicas (CSIC-Universidad de Sevilla)

Avda. Américo Vespucio, 49

41092 Sevilla, Spain

${ }^{\mathrm{b}}$ Laboratorio de Rayos-X. CITIUS. Avda. Reina Mercedes, 4

41012 Sevilla, Spain

${ }^{c}$ Instituto Ciencia de Materiales de Sevilla (CSIC-Universidad de Sevilla)

Avda. Américo Vespucio, 49

41092 Sevilla, Spain

${ }^{\mathrm{d}}$ Centers for the Development of Nanoscience and Nanotechnology, CEDENNA, 9170124 Santiago, Chile

\section{ABSTRACT}

Bentonite is accepted as the best clay material for the engineered barrier of Deep Geological Repositories (DGRs). The performance of clay as the main component of the engineered barrier in the DGR has been intensively studied and the structure of the selected clay mineral play a crucial role. In this sense, a new family of synthetic

\footnotetext{
*Corresponding author: E-mail: alba@icmse.csic.es
} 
swelling silicates, Na-Mica-n, with tuned layer charge (n) values between 2.0 and 4.0 per unit cell has recently been synthesized and a general synthetic method has been reported. These swelling high-charge micas could be highly valuable for the decontamination of harmful cations. The ability of these micas to immobilize $\mathrm{Eu}^{3+}$ under subcritical conditions has been probed. The adsorption was in both non-specific sites (cation exchange mechanism) and specific sites (chemical reaction or surface defects adsorption). Moreover, its adsorption capacity, under the same conditions is higher than in saponite and far superior to the bentonites.

Keywords: Micas, engineered barrier, radionuclides, adsorption, chemical reaction 


\section{Introduction}

The management of radioactive waste containing actinides is currently a key environmental problem due to the need for its long-term, safe and efficient storage. The deep geological repository (DGR) is based on a passive multi-barrier system approach that combines waste packages, engineered seals, and bedrock whereby the major responsibility for safety falls on the engineered barrier system (EBS). Nowadays, bentonite is accepted as the best clay material for the engineered barrier of DGRs $[1,2]$ Under saturation conditions, bentonite, due to its high content of smectite, swells and seals the tunnel, restricting almost all flow of water inside the EBS [1]. Moreover, a clay barrier is able to delay the diffusion and immobilize, in certain experimental conditions, the radioactive wastes through a physical-chemical mechanism, such as adsorption, precipitation or even a chemical reaction including the formation of secondary stable mineral phases.

The performance of clay as the main component of the engineered barrier in the DGR has been intensively studied, e.g. its response to intense irradiation [3] its sorption properties [2,4], colloid formation reactions[5], and the connections between sorption chemistry and mechanical compaction [6]. Regarding the clay adsorption properties, recent studies highlight the existence of an additional retention mechanism $[7,8]$. The systematic study of the interaction of the Rare Earth Element (REE) cations as actinides chemical analogues, with natural and artificial clay minerals, reveal a reaction mechanism, based on the chemical interaction between the lanthanide cations and the orthosilicate anions of the lamellar structure [9,10]. At subcritical conditions, (temperature and pressure), an insoluble and chemically stable phase, $\mathrm{REE}_{2} \mathrm{Si}_{2} \mathrm{O}_{7}$, is generated [11]. 
Chaín et al. [12] observed that, in the context of engineered barrier safety, the structure of the selected clay mineral should fulfil the following conditions: 2:1 sheets stacking with complete occupancy of the octahedral sheet, the absence of octahedral isomorphic substitution, isomorphic substitution in tetrahedral sheet and sodium as interlayer cation.

Although swelling 2:1 layered silicates have traditionally been considered to be those containing a total layer charge between 0.4 and 1.8 per unit cell (smectite and vermiculite groups), a new family of synthetic swelling silicates, Na-Mica-n: $\mathrm{Na}_{\mathrm{n}}\left(\mathrm{Si}_{8-}\right.$ $\left.{ }_{n} \mathrm{Al}_{\mathrm{n}}\right)\left(\mathrm{Mg}_{6}\right) \mathrm{O}_{20} \mathrm{~F}_{4}$, with tuned layer charge (n) values between 2.0 and 4.0 per unit cell has recently been synthesized $[13,14,15]$ and a general synthetic method has been reported [16]. These swelling high-charge micas, in which the layer charge can be adjusted, could be highly valuable for the decontamination of harmful metal cations via ion-exchange reactions [17] and for the selective removal of highly radioactive ions [16] and hydrocarbon molecules [18].

If uranium ( $95 \%$ of the spent fuel) is disregarded, an average composition of the spent-fuel pellets would be approximately 18 mass $\%$ of plutonium and 2 mass $\%$ of equally distributed neptunium and americium, with the remaining actinides as minor elements [19]. Thus, it is of great interest to explore the reaction capacity of this new family of clay minerals, Na-Mica-n, with the trivalent actinides $\mathrm{Am}^{3+}, \mathrm{Pu}^{3+}$ and $\mathrm{Cm}^{3+}$, the $\mathrm{Eu}^{3+}$ being the appropriate stable cation to act as their chemical simulator $[20,21,22,23]$.

In previous studies of interaction of $\mathrm{Eu}^{3+}$ with clay minerals, the ion exchange reaction was the primary mechanism of adsorption in the temperature range between $25^{\circ}$ and $150^{\circ} \mathrm{C}[9,24,25,26,27]$. However, at higher temperatures, a chemical interaction between $\mathrm{Eu}^{3+}$ and clay minerals was also found [9]. Although the expected conditions in 
the DGRs do not exceed $150^{\circ} \mathrm{C}$, many studies simulating the storage operations were carried out at temperatures up to $350{ }^{\circ} \mathrm{C}$ to increase the reaction kinetic [28].

Therefore, the aim of this work is the study of the ability of immobilizing $\mathrm{Eu}^{3+}$, as trivalent actinide simulator, for a family of synthetic high-charged micas, Na-Mica-n, at pressure and temperature subcritical conditions (similar to long-term conditions of the DGRs).

\section{Material and methods}

\subsection{Synthesis of Na-Mica-n.}

A procedure similar to that described by Alba et al. [16] was employed. Nearstoichiometric powder mixtures with the molar compositions $(8-n) \mathrm{SiO}_{2},(n / 2) \mathrm{Al}_{2} \mathrm{O}_{3}, 6$ $\mathrm{MgF}_{2}$, and (2n) $\mathrm{NaCl}$ were used to synthesize Na-Mica- $n(n=2$ and 4). The starting materials were $\mathrm{SiO}_{2}$ from Sigma (CAS no. $112945-52-5,99.8 \%$ purity), $\mathrm{Al}(\mathrm{OH})_{3}$ from Riedel-de Haën (CAS no. 21645-51-2, 99\% purity), $\mathrm{MgF}_{2}$ from Aldrich (CAS no. 20831-0, 98\% purity), and $\mathrm{NaCl}$ from Panreac (CAS no. 131659, 99.5\% purity). All reagents were mixed and ground vigorously before heating up to $900{ }^{\circ} \mathrm{C}$ in a Pt crucible for $15 \mathrm{~h}$. After cooling, the solids were washed with deionized water and dried at room temperature. The as-synthesized samples are named Na-Mica- $n$ ( $n$ ranging between 2 and 4) and with a theoretical cation exchanged capacity (CEC) based of $247.5 \mathrm{meq} / 100 \mathrm{~g}$ (Na-Mica-2) and 469.5 meq/100 g (Na-Mica-4).

\subsection{Hydrothermal treatments}


Three hundred milligrams of the powdered samples were dispersed in the $50 \mathrm{ml}$ of $5 \cdot 10^{-2} \mathrm{M} \mathrm{Eu}\left(\mathrm{NO}_{3}\right)_{3}$ solutions and were heated in a stainless steel reactor [29], at the temperatures and times summarized in Table 1 . The reaction products were collected by filtering using a Millipore filter with $0.45 \mu \mathrm{m}$ pore diameter, washed with distilled water, and dried in air at $60^{\circ} \mathrm{C}$. The reaction solution and the washing liquid were kept for quantitative analysis of europium by ICP-AES. The solid samples were collected for structural analysis by XRD and SEM/EDX.

\subsection{Characterization}

Europium concentrations in the initial solutions $\left(\mathrm{C}_{\mathrm{i}}, \mathrm{meq} / \mathrm{L}\right)$ and in the supernatants obtained after the hydrothermal treatments $\left(\mathrm{C}_{\mathrm{eq}}\right.$, meq/L) were analyzed at the CITIUS microanalysis laboratory (University of Seville, Spain) by using Inductively Coupled Plasma-Atomic Emission Spectrometry (ICP-AES) (HORIBA JOBIN YVON-ULTIMA 2). The $\mathrm{K}_{\mathrm{d}}$ values $(\mathrm{L} / \mathrm{Kg})$ were calculated from the quantification of europium concentration in final contact solution $\left(\mathrm{C}_{\mathrm{eq}}, \mathrm{meq} / \mathrm{L}\right)$ and the adsorbed concentration $\left(\mathrm{C}_{\text {sor }}=\left(\mathrm{C}_{\mathrm{i}}-\mathrm{C}_{\mathrm{eq}}\right) \cdot \mathrm{V} / \mathrm{m}, \mathrm{meq} / \mathrm{Kg}\right)$ according to the following equation:

$$
K_{d}=\frac{C_{s o r}}{C_{e q}}
$$

where $m$ is the mass of materials and $V$ is the volume of the supernatants.

X-ray diffraction (XRD) patterns were obtained at the CITIUS X-ray laboratory (University of Seville, Spain) using a Bruker D8 Advance instrument equipped with a $\mathrm{Cu} \mathrm{K} \mathrm{K}_{\alpha}$ radiation source operating at $40 \mathrm{kV}$ and $40 \mathrm{~mA}$. The powder XRD patterns were obtained in the $2 \theta$-range $3-70^{\circ}$ with a step size of $0.015^{\circ}$ and a time step of $0.1 \mathrm{~s}$. Crystalline phase identification was carried out using the DIFFRAC ${ }^{\text {plus }}$ Evaluation 
package (@2010 Bruker AXS GmbH, Karlsruhe, Germany) using the diffraction database ICDD PDF-4+ 2014.

When crystalline phases could not be identified by XRD, scanning electron microscopy (SEM/EDX) was chosen. Morphologies and chemical compositions were analyzed in Microscopy Service of ICMS (CSIC-Universidad de Sevilla) with a SEMFEG HITACHI S- 4800; a scanning electron microscope equipped with an Xflash 4010 (Bruker) for energy dispersive X-ray (EDX) analysis.

\section{Result and discussion}

\subsection{Influence of the reaction time}

The adsorption capacity of micas as a function of the reaction time has been followed by the comparison of the $\mathrm{Eu}^{3+}$ concentration in the initial solution and in the supernatant after the hydrothermal treatment at $300{ }^{\circ} \mathrm{C}$, in a time interval between $0 \mathrm{~h}$ and 1 month. It is noted that at $0 \mathrm{~h}$ (Fig. 1a), $\mathrm{Eu}^{3+}$ adsorption occurs in the order of the cation exchange capacity of the micas (CEC) for Na-Mica-4 and slighter higher in the case of Na-Mica-2. However, after 2 days (Fig. 1a), the adsorption is far higher than its exchange capacity denoting that other mechanisms, such as precipitation, adsorption sites or specific chemical reaction between $\mathrm{Eu}^{3+}$ and the silicate matrix, are involved. Likewise, a progressive adsorption increasing is observed over the time and an equilibrium state is reached after 1 week for Na-Mica-2 and after 2 weeks for Na-Mica-

4. The adsorbed concentration increases as the layer charge of the mica increases, being $84.8 \%$ and $81.3 \%$ for Na-Mica-4 and Na-Mica-2, respectively. 
The analysis of the evolution of the adsorption sites with respect to time has been analyzed thorough the evolution of $\mathrm{K}_{\mathrm{d}}$ values vs \% CEC (Fig. 1b). When the adsorbed amount is close to the CEC of mica, the $\mathrm{K}_{\mathrm{d}}$ value is very small. This is because adsorption operates mainly by the cation exchange mechanism (adsorption on non-specific sites). However, when the quantities needed to meet the CEC of mica are overcome, the $K_{d}$ values increase sharply due to an increasing adsorption on specific sites (i.e. adsorption defects surface, chemical reaction ...) [30]. As the layer charge increases, an increasing of specific sites adsorption (higher $\mathrm{K}_{\mathrm{d}}$ values) is observed. This agrees with an increment of weaken bonds, Al-O-Al and Al-O-Si, in Na-Mica-4 vs NaMica-2, and thus, more surface defects and specific sites are generated [31].

The XRD patterns (Fig. 2 and Fig. 3) were analyzed to shed a light on the adsorption mechanisms when the adsorption is higher than the CEC of micas. The XRD patterns of the initial samples correspond with those described for Na-Mica-n [16], showing a small impurity of sodalite (marked with $s$ in the pattern), and the $2 \theta$ of the 001 reflection corresponds to a basal space of $12.2 \AA$ due to the hydrated $\mathrm{Na}^{+}$cation in the interlayer space [32]. After the hydrothermal treatment at $300{ }^{\circ} \mathrm{C}$ for 0 hours, the Na-Mica-4 shows a XRD pattern similar to the initial sample which indicates that the layered structure remains with a hydrated monovalent cation in the interlayer space. In contrast, the Na-Mica-2 XRD pattern exhibits two 001 reflections families, one more intense reflection corresponding to a basal spacing of $14.5 \AA$, corresponding to the hydrated $\mathrm{Eu}^{3+}$ cations [33] and other minor 001 reflection similar to that of initial mica. The Na-Mica-2 structural changes at 0 hours support the supernatant analysis, showing $\mathrm{Eu}^{3+}$ adsorption to satisfy its CEC (Fig. 1a) and involving a low $\mathrm{K}_{\mathrm{d}}$ adsorption on nonspecific sites (Fig. 1b). In the case of Na-Mica-4, as the adsorbed $\mathrm{Eu}^{3+}$ is below its CEC 
then both $\mathrm{Eu}^{3+}$ and $\mathrm{Na}^{+}$are located in the interlayer space and it can explain the lowest swelling.

The XRD patterns of the micas after the hydrothermal treatment at $300{ }^{\circ} \mathrm{C}$ for 2 days are characterized, firstly, by a background due to the partial amorphization of the mica, as a stage prior to the chemical reaction and as previously observed in other $2: 1$ phyllosilicates [7]. In addition, typical reflections of layered aluminosilicates disappear and small diffraction peaks appear due to the crystallization of secondary phases resulting from the interaction of the $\mathrm{Eu}^{3+}$ with the mica framework. This agrees with the increased $\mathrm{Eu}^{3+}$ adsorption, above the $\mathrm{CEC}$, and $\mathrm{K}_{\mathrm{d}}$ value due to adsorption on specific sites. These phases grow up to 1 week reaction time and remain practically constant at 1 month.

The comparative analysis of the crystalline phases containing $\mathrm{Eu}^{3+}$ generated when micas were submitted to the hydrothermal treatment at $300{ }^{\circ} \mathrm{C}$ for 1 month (Fig. 3) shows that in both micas, aluminates and silicates of europium are formed but the proportion varies depending on the layer charge. So, as the isomorphic substitutions of $\mathrm{Si}$ by $\mathrm{Al}$ increases, Na-Mica-4, more aluminates than silicates are formed and among silicates, orthosilicates are more favored than disilicates.

The samples submitted at hydrothermal treatment for 0 hours and 2 days have been analyzed by SEM/EDX. Fig. 4a and $4 b$ show the EDX spectra of the Na-Mica-2, initial and after hydrothermal treatment for 0 hours. It is observed that after the treatment, the amount of sodium has decreased while the content of europium increases. This justifies the increase interlayer space observed by XRD and it is due to an ion exchange process between $\mathrm{Eu}^{3+}$ and $\mathrm{Na}^{+}$. The EDX spectrum of the particles after the treatment show that the silicon signal increases, which can be explained by the formation of amorphous phases containing silicon. No morphological changes are 
observed in micas after the treatment (Fig. 4b). The micrographs obtained by SEM and the EDX analysis of Na-Mica-4 initial and after hydrothermal treatment at $300{ }^{\circ} \mathrm{C}, 0$ hours are shown in Fig. 5. The EDX spectra of the analyzed particles do not differ significantly despite of the treatment and the lamellar morphology remains. In particular, no lines associated with Eu appear, this verifies the results obtained by XRD, where the Na-Mica-4 does not swell.

After the hydrothermal treatment of Na-Mica-2 for 2 days, three areas of the sample (Fig. 6) were analyzed. The three EDX spectra are characterized by the absence of $\mathrm{K}_{\alpha}$ lines of $\mathrm{Na}$ and $\mathrm{Mg}$, involving the deterioration of the structure of the mica, and the emergence of $\mathrm{L}_{\alpha}$ line of Eu. The particles morphology has changed and larger aggregates have been formed. This agrees with the supernatant analysis that showed Eu adsorption of $65.1 \%$ and the minor development of aluminate crystal phases and europium silicates. After 2 days of hydrothermal treatment, Na-Mica-4 (Fig.

7) the EDX spectra shows the $\mathrm{L}_{\alpha}$ lines of Eu and a decrease of the $\mathrm{K}_{\alpha}$ lines of $\mathrm{Na}$ and Mg. Differences in morphology are also observed: large elongated particles and large amount of europium (Fig. 7b) and irregular particles rich on $\mathrm{Al}$ and $\mathrm{Si}$ and lower Eu content (Fig.7c). A small amount of $\mathrm{Mg}$ is also seen after the treatment, thus, magnesium has not been fully leached during the formation of amorphous phases.

\subsection{Influence of the reaction temperature}

To analyze the effect of temperature on the retention of $\mathrm{Eu}^{3+}$ by micas, hydrothermal treatments at $150{ }^{\circ} \mathrm{C}, 200{ }^{\circ} \mathrm{C}$ and $300{ }^{\circ} \mathrm{C}$ for 1 month have been carried out. 
Upon determination of $\mathrm{Eu}^{3+}$ in solution by ICP-AES, the amount of Eu adsorbed and $K_{d}$ values by Na-Mica-n $(n=2$ and 4$)$ as function of temperature treatment were calculated (Table 2). It is noted that even at the lowest temperature the amount of adsorbed $\mathrm{Eu}^{3+}$ is greater than the CEC of mica, denoting that other mechanisms such as precipitation, site-specific adsorption or reaction chemistry between $\mathrm{Eu}^{3+}$ and silicate framework are involved. At $200{ }^{\circ} \mathrm{C}$, a slight increase in the absorption of $\mathrm{Eu}^{3+}$ is observed and it increases sharply at $300{ }^{\circ} \mathrm{C}$. In the temperature range $300{ }^{\circ} \mathrm{C}-200{ }^{\circ} \mathrm{C}$, more adsorption is observed in the Na-Mica-4 than in the Na-Mica-2.

The analysis of the evolution of the adsorption sites with respect to temperature was carried out by studying the evolution of $\mathrm{K}_{\mathrm{d}}$ values (Table 2). It is noted that the specific adsorption sites is favored (increases $K_{d}$ ) with increasing temperature, even the lowest $\mathrm{K}_{\mathrm{d}}$ values are above those observed when only non-specific sites adsorption operates $\left(\mathrm{K}_{\mathrm{d}}\right.$ ca. $30 \mathrm{~L} / \mathrm{Kg}$, see Fig. 1$)$, confirming that even at $150{ }^{\circ} \mathrm{C}$ there was some involvement of adsorption on specific sites. When the evolution of the $K_{d}$ based on $\%$ CEC is analyzed, it is observed that as they are exceeding the quantities needed to meet the CEC of mica, the $K_{d}$ values abruptly increases due to adsorption on specific sites (i.e. adsorption surface defects in chemical reaction ...). In this case, differentiating behavior between the micas is observed, as the layer charge increases the participation of specific sites also increases. This agrees with increasing of the Al-O-Al and Al-O-Si bonds in Na-Mica-4 vs Na-Mica-2, because of these bonds are weaker [31] then surface defects and specific sites are generated. The differences between the two micas increase with increasing temperature.

A comparison of the adsorption capacity of $\mathrm{Eu}^{3+}$ for synthetic micas over other natural 2:1 phyllosilicates has been carried out (Table 3). It is noted, first, that at both extreme temperatures, adsorption capacity of synthetic micas is practically double than 
in saponite and approximately ten times higher than for the bentonites [34]. This confirms that a total occupation of the octahedral sheet (saponite, Na-Mica-n) and substitutions of Si by Al in the tetrahedral sheet (Na-Mica-n vs saponite) favor the immobilization of $\mathrm{Eu}^{3+}$ by chemical reaction with the 2:1 phyllosilicate framework. The minor difference between the two Na-Mica-n can be explained by the destabilizing factor of increasing substitutions of Al, as previously observed in other systems [7].

A detailed analysis of the structural changes occurring in the mica as result of hydrothermal treatment was carried out by XRD (Fig. 8). The XRD patterns of the samples after the treatments at $150{ }^{\circ} \mathrm{C}$ and $200{ }^{\circ} \mathrm{C}$ for 1 month show significant deterioration of the long-range order of mica framework, so that hkl reflections disappear and crystallize new phases, being more evident in the case of Na-Mica- 2 . However, rational number of $00 \mathrm{l}$ reflections are evident, in the case of Na-Mica-2 it corresponds to a single $00 \mathrm{l}$ family with a value of basal space of $14.5 \AA$, corresponding to hydrated $\mathrm{Eu}^{3+}$ in the interlayer space [33] while in the Na-Mica-4 coexist different hydration states of the layers.

In the case of Na-Mica-2, new reflections are observed and correspond to the crystallization of secondary phases resulting from the micas disruption and from the interaction of $\mathrm{Eu}^{3+}$ with the mica framework. This is consistent with the adsorption of $\mathrm{Eu}^{3+}$ over its $\mathrm{CEC}$ and $\mathrm{K}_{\mathrm{d}}$ value above that observed in the case of ion exchange adsorption. These crystalline phases increase with temperature. In the case of Na-Mica4, the degree of crystallinity of the samples decreases significantly.

Electron micrographs and EDX analysis of the Na-Mica-n and obtained after the hydrothermal treatments at different temperatures show differences in the morphology respect to the mica. After the hydrothermal treatment at $150{ }^{\circ} \mathrm{C}$ for one month of $\mathrm{Na}$ Mica-2 (Fig. 9), the majority of the particles kept the lamellar morphology but with 
different compositions. Thus, the composition of the particle of Fig. 9b would be consistent with ion exchange as $\mathrm{L}_{\alpha}$ lines of Eu are observed on the EDX spectrum and $\mathrm{K}_{\alpha}$ line of $\mathrm{Na}$ is absent. Other particles has an elongated morphology (Fig. 4c) and contains europium and less amount of magnesium than in the mica, which would be compatible with the formation of europium silicates (observed by XRD) and with the Eu adsorption above its CEC. Treatment at $200{ }^{\circ} \mathrm{C}$ produces a similar effect on the particles but showing a higher number of particles with higher content of Eu.

After the hydrothermal treatment at $150^{\circ} \mathrm{C}$ for a month of Na-Mica-4 (Fig. 10), the most of the particles show a laminar morphology supported by EDX spectrum, which inferred an ion exchange of $\mathrm{Na}^{+}$by $\mathrm{Eu}^{3+}$ and an apparent deterioration of the structure with $\mathrm{F}$ and $\mathrm{Mg}$ leaching. Alongside these particles, other plank-like particles appear with a high Eu content and $\mathrm{Si}$, which may be compatible with europium silicates phases but they were not observed by XRD. Similar results are observed after treatment at $200^{\circ} \mathrm{C}$.

\section{Conclusions}

Synthetic high-charged micas are able to immobilize $\mathrm{Eu}^{3+}$ cations at temperatures close to those expected in the DGRs thorough the adsorption on nonspecific sites (cation exchange mechanism) and on specific sites (chemical reaction or surface defects adsorption). Moreover, its adsorption capacity, under the same conditions is higher than in saponite and far superior to the bentonites.

The adsorption on specific and non-specific sites depends on the mica nature, temperature and time reaction. The availability of specific sites depends on the layer charge; it is higher for the Na-Mica-4 than for Na-Mica-2. At a given time reaction, the 
availability of specific sites decreases as the temperature decreases, and, at a temperature, the availability of specific sites increases when the reaction time increases.

In addition, a chemical reaction has been observed, and, in general, adsorption is favored with higher aluminum content (higher layer charge) where aluminates are preferably forming instead of silicates phases.

\section{Acknowledgements}

We would like to thank the Junta de Andalucía (Spain) and FEDER (Proyecto de Excelencia de la Junta de Andalucía, project P12-FQM-567) for providing financial support. We also thank to ENRESA for their economical support (contract $\mathrm{n}^{\mathrm{o}}$ 0079000237). Dr. Pavón also thanks her grant project, approved by the Andalucía Talent Hub Program launched by the Andalusian Knowledge Agency, co-funded by the European Union's Seventh Framework Program, Marie Skłodowska-Curie actions (COFUND - Grant Agreement $n^{\circ}$ 291780) and the Ministry of Economy, Innovation, Science and Employment of the Junta de Andalucía.

\section{References}

[1] S.W. Bailey, Structures of layer silicates. In Crystal Structures of Clay Minerals and their X-ray Identification (eds. Brindley, G.W., Brown, G and Schafer, T. (1980).

[2] M.M. Fernandes, B. Baeyens, R. Dahn, A.C. Scheinost, M.H. Bradbury, U(VI) sorption on montmorillonite in the absence and presence of carbonate: A macroscopic and microscopic study, Geochim. Cosm. Acta 93 (2012) 262-277.

[3] S. Sorieul, T. Allard, L.M. Wang, C. Grambin-Lapeye, J. Lian, G. Calas, R.C. Ewing, RadiationStability of Smectite, Envir. Sci. Tech. 42 (2008) 8407-8411.

[4] T. Stumpf, A. Bauer, F. Coppin, J. Kim, Time-resolved laser fluorescence spectroscopy study of 
the sorption of Cm(III) onto smectite and kaolinite, Envir. Sci. Tech. 35 (2001) 3691-3694.

[5] M. Bouby, H. Geckeis, J. Lutzenkirchen, S. Mihai, T. Schafer, Interaction of bentonite colloids with $\mathrm{Cs}$, Eu, Th and $\mathrm{U}$ in presence of humic acid: A flow field-flow fractionation study, Geochim. Cosm. Acta, 75 (2011) 3866-3880.

[6] A.W. Miller, Y.F. Wang, Radionuclide Interaction with Clays in Dilute and Heavily Compacted Systems: A Critical Review, Envir. Sci. Tech. 46, (2012) 1981-1994.

[7] M.D. Alba, P. Chain, M.M. Orta, Chemical reactivity of argillaceous material in engineered barrier Rare earth disilicate formation under subcritical conditions, Appl. Clay Sci. 43 (2009) 369-375.

[8] J.M. Trillo, M.D. Alba, R. Alvero, M.A. Castro, A. Muñoz-Paez, J. Poyato, Interaction of Multivalent Cations with Layered Clays - Generation of Lutetium Disilicate Upon Hydrothermal Treatment of Lu-Montmorillonite, Inor. Chem. 33 (1994) 3861-3862.

[9] M.D. Alba, M.A. Castro, P. Chaín, S. Hurtado, M.M. Orta, M.C. Pazos, M. Villa, Interaction of Euisotopes with saponite as a component of the engineered barrier, Appl. Clay Sci. 52 (2011) 253-257.

[10] M.D. Alba, P. Chain, Interaction between Lu cations and 2:1 alumino silicates under hydrothermal treatment, Clays Clay Miner. 53 (2005) 200537-44.

[11] M.D. Alba, P. Chain, M.M. Orta, Rare-earth disilicate formation under Deep Geological Repository approach conditions, Appl. Clay Sci. 46 (2009) 63-68.

[12] P. Chaín, A. Cota, S. El Mrabet, E. Pavón, M.C. Pazos, M.D. Alba, Evaluation of rare earth on layered silicates under subcritical conditions: Effect of the framework and interlayer space composition, Chem. Geol. 347 (2013), 208-216.

[13] M. Gregorkiewitz, J. A. Rausell-Colom, Characterization and properties of a new synthetic silicate with highly charged mica-type layers, Amer. Miner. 72 (1987) 515-527.

[14] M. Park, D.H. Lee, C.L. Choi, S.S. Kim., K.S. Kim, J. Choi, Pure Na-4-mica: Synthesis and Characterization, Chem. Mater. 14 (2002) 2582-2589.

[15] S. Komarneni, R. Ravella, M. Park Swelling mica-type clays: Synthesis by $\mathrm{NaCl}$ melt method, NMR characterization and cation exchange selectivity, J. Mater. Chem. 15 (2005) 4241-4245.

[16] M.D. Alba, M.A. Castro, M. Naranjo, E. Pavón, Hydrothermal reactivity of Na-n-micas ( $\mathrm{n}=2,3$, 4), Chem. Mater. 18 (2006) 2867-2872.

[17] R. Ravella, S. Komarneni, C.E. Martinez, Highly charged swelling mica-type clays for selective $\mathrm{Cu}$ exchange, Env. Sci. Tech. 42 (2008) 113-118. 
[18] M.D. Alba, M.A. Castro, M.M. Orta, E. Pavón, C. Pazos, J. Valencia, Formation of organo-highly charged mica, Langmuir 27 (2011) 9711-9718.

[19] J. Astudillo, El almacenamiento geológico profundo de los residuos radiactivos de alta actividad. Principios básicos y tecnología. Editorial ENRESA, 2001.

[20] J.M. Oades, Interactions of polycations of aluminum and iron with clays, Clay. Clay. Miner. 32 (1984) 49-57.

[21] D.E. Morris, C.J. Chisholm-Brause, M.E. Barr, S.D. Condrason, P.G. Eller, Optical spectroscopic studies of the sorption of $\mathrm{UO}_{2}{ }^{2+}$ species on a reference smectite, Geochim. Cosmochim. Acta 58 (1994) 3613-3623.

[22] M.H. Bradbury, B. Baeyens, H. Geckeis, Th Rabung, Sorption of $\mathrm{Eu}(\mathrm{III}) / \mathrm{Cm}(\mathrm{III})$ on Camontmorillonite and Na-illite. Part 2: Surface complexation modelling, Geochim. Cosm. Acta 69 (2005) 5403-5412.

[23] Q.H. Fan, X.L Tan, J.X Li, X.K. Wang, W.S. Wuand, G., Montavon Sorption of Eu(III) on Attapulgite Studied by Batch, XPS, and EXAFS Techniques, Envir. Sci. Tech. 43 (2009) 57765782.

[24] S. Jennings, G.R. Thompson, Diagenesis of pliopleistocene sediments of the colorado river-delta, southern-california, J. Sediment. Petrol. 56, (1986) 89-98.

[25] D.D. Eberl, B. Velde, T. McCormick, Synthesis of illite-smectite from smectite at earth surface temperatures and high pH, Clay Miner. 28, (1993) 49-60.

[26] R.B. Heimann, Bronsted acidification observed during hydrothermal treatment of a calcium montmorillonite, Clay. Clay. Miner. 41 (1993) 718-725.

[27] C. Chisholm-Brause, S.D. Conradson, C.T. Buscher, P.G. Eller, D.E. Morris Speciation of uranyl sorbed at multiple binding-sites on montmorillonite, Geochim. Cosm. Acta 58 (1994) 3625-3631.

[28] N.A. Chapman, J.A.T. Smellie, Special issue - natural analogs to the conditions around a final repository for high-level radioactive-waste - introduction and summary of the workshop, Chem. Geol. 55, (1986) 167-173.

[29] A.C. Perdigón, Estudio del sistema saponita/Lu(NO3)3/H2O en condiciones hidrotérmicas, University of Sevilla, Spain, 2002. 
[30] E. Galunin, M.D. Alba, M.A. Avilés, M.J. Santos, M. Vidal, Reversibility of La and Lu sorption onto smectites: Implications for the design of engineered barriers in deep geological repositories, J. Hazar. Mater. 172 (2009) 1198-1205.

[31] D.J. Stein, F.J. Spera, Experimental rheometry of melts and supercooled liquids in the system naalsio4-sio2 - implications for structure and dynamics, Am. Miner.78 (1993) 710-723.

[32] M.D. Alba, A.I. Becerro, M.A. Castro, A.C. Perdigón, Hydrothermal reactivity of Lu-saturated smectites: Part I. A long-range order study, Am. Miner. 86 (2001) 115-123.

[33] E.J.M. Hensen, T.J. Tambach, A. Bliek, B. Smit, Adsorption isotherms of water in Li-, Na-, and K-montmorillonite by molecular simulation, J. Chem. Phys. 115 (2001) 3322-3329.

[34] M. Villa-Alfageme, S. Hurtado, M.A. Castro, S. El Mraber, M.M. Orta, M.C. Pazos, M.D. Alba, Quantification and comparison of the reaction properties of FEBEX and MX-80 clays with saponite: Europium immobilisers under subcritical conditions, Appl. Clay Sci. 101 (2014) 10-15. 
Table 1.

Temperatures and time of the hydrothermal treatment with $\mathrm{Eu}^{3+}$ of Na-Mica-n ( $\mathrm{n}=2$ and 4).

\begin{tabular}{ccccccc}
\hline Temperature & \multicolumn{5}{c}{ Time } \\
\cline { 2 - 6 }$\left({ }^{\circ} \mathrm{C}\right)$ & $0 \mathrm{~h}$ & $2 \mathrm{~d}$ & $4 \mathrm{~d}$ & $1 \mathrm{w}$ & $2 \mathrm{w}$ & $1 \mathrm{~m}$ \\
\hline 100 & & & & & & \\
200 & & & & & & \\
300 & & & & & & \\
\hline
\end{tabular}

Table 2.

Amount of adsorbed $\mathrm{Eu}^{3+}, \mathrm{K}_{\mathrm{d}}$ value and \% $\mathrm{CEC}$ satisfied of Na-Mica-n $(\mathrm{n}=2$ and 4) after hydrothermal treatment with $\mathrm{Eu}^{3+}$ during 4 weeks as a function of the reaction temperature.

\begin{tabular}{ccccc}
\hline samples & $\begin{array}{c}\mathrm{T} \\
\left({ }^{\circ} \mathrm{C}\right)\end{array}$ & $\begin{array}{c}\mathrm{C}_{\text {sor }} \\
(\mathrm{meq} / 100 \mathrm{~g})\end{array}$ & $\begin{array}{c}\mathrm{K}_{\mathrm{d}} \\
(\mathrm{L} / \mathrm{Kg})\end{array}$ & \%CEC \\
\hline \multirow{2}{*}{ Na- } & 150 & 972.1 & 73.5 & 392.7 \\
Mica-2 & 200 & 906.5 & 74.3 & 366.2 \\
& 300 & 2254.6 & 539.1 & 910.8 \\
Na- & 150 & 828.7 & 65.2 & 176.5 \\
Mica-4 & 200 & 1116.5 & 108.0 & 237.8 \\
& 300 & 2339.4 & 669.3 & 498.3 \\
\hline
\end{tabular}

Table 3.

Amount of adsorbed $\mathrm{Eu}^{3+}$ (meq $\mathrm{Eu}^{3+} / 100 \mathrm{~g}$ clay mineral) and in parenthesis the percentage of retention.

\begin{tabular}{cccccc}
\hline $\mathrm{T}$ & Saponite $^{\mathrm{a}}$ & FEBEX $^{\mathrm{a}}$ & MX-80 & Na-Mica-2 & Na-Mica-4 \\
\hline \multirow{2}{*}{$300{ }^{\circ} \mathrm{C}$} & 1167.8 & 398.1 & 191.1 & 2254.6 & 2339.4 \\
& $(37.7 \%)$ & $(12.9 \%)$ & $(6.2 \%)$ & $(82.4 \%)$ & $(84.1 \%)$ \\
\multirow{2}{*}{$150^{\circ} \mathrm{C}$} & 400.0 & 83.34 & 98.0 & 972.1 & 828.7 \\
& $(12.9 \%)$ & $(2.7 \%)$ & $(3.2 \%)$ & $(35.5 \%)$ & $(30.3 \%)$ \\
\hline${ }^{a}$ ref. 34 & & & & &
\end{tabular}


2

Fig. 1. a) Amount of adsorbed $\mathrm{Eu}^{3+}$ on Na-Mica-n ( $n=2$ and 4) after hydrothermal treatment at $300 \stackrel{\circ}{ } \mathrm{C}$ as a function of the reaction time. b) Variation of $K_{d}$ vs percentage of CEC satisfied. Dash line corresponds to the CEC of Na-Mica-2 and solid line corresponds to the CEC of NaMica-4.

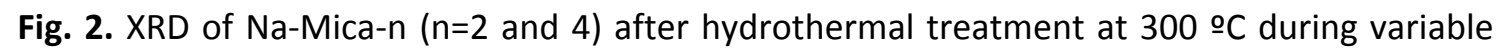
reaction time. $s=$ sodalite $\left(\mathrm{Al}_{6} \mathrm{Na}_{8}\left(\mathrm{SiO}_{4}\right)_{6} \mathrm{Cl}_{2}\right)$, PDF 04-09-5289; V=vermiculite, PDF 01-76-6603; $\mathrm{B}=$ bayerite $\left(\mathrm{Al}(\mathrm{OH})_{3}\right)$, PDF 01-77-0250; $d=$ dikite $\left(\mathrm{Al}_{2} \mathrm{Si}_{2} \mathrm{O}_{5}(\mathrm{OH})_{4}\right)$, PDF 00-10-430; a=anthophyllite $\left(\mathrm{Mg}_{7}\left(\mathrm{Si}_{8} \mathrm{O}_{22}(\mathrm{OH})_{2}\right)\right.$, PDF 01-75-0909; b=boehmite (AIO(OH)), PDF 00-21-1307; $h=\mathrm{NaH}_{3} \mathrm{SiO}_{4}, \mathrm{PDF}$ 00-16-553; +=EuAlO 3 , PDF 04-06-5193; ${ }^{\wedge}=\mathrm{A}^{-} \mathrm{Eu}_{2} \mathrm{SiO}_{4}, \mathrm{PDF}$ 01-73-1156; * ${ }^{*}-\mathrm{Eu}_{2} \mathrm{Si}_{2} \mathrm{O}_{7}$, PDF 00-23-

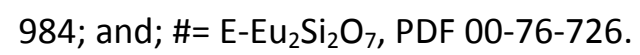

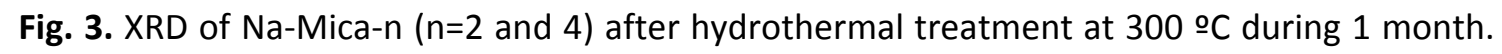

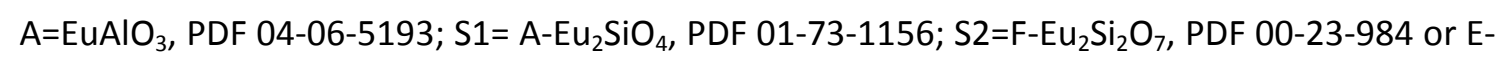
$\mathrm{Eu}_{2} \mathrm{Si}_{2} \mathrm{O}_{7}, \mathrm{PDF}$ 00-76-726.

Fig. 4. SEM imagine and EDX spectra of Na-Mica-2: a) initial; and; b) after hydrothermal

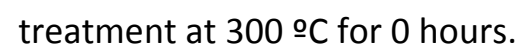

Fig. 5. SEM imagine and EDX spectra of Na-Mica-4: a) initial; and; b,c) after hydrothermal treatment at $300 \stackrel{\circ}{\mathrm{C}}$ for 0 hours.

Fig. 6. SEM imagine and EDX spectra of Na-Mica-2: a) initial; and; b-d) after hydrothermal treatment at $300 \stackrel{\circ}{\circ}$ for 2 days.

Fig. 7. SEM imagine and EDX spectra of Na-Mica-4: a) initial; and; b-d) after hydrothermal

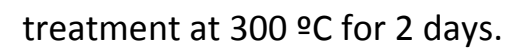

Fig. 8. XRD of Na-Mica- $n(n=2$ and 4 ) after hydrothermal treatment during 1 month at variable reaction temperature. $s=$ sodalite $\left(\mathrm{Al}_{6} \mathrm{Na}_{8}\left(\mathrm{SiO}_{4}\right)_{6} \mathrm{Cl}_{2}\right)$, PDF 04-09-5289; $d=$ dikite $\left(\mathrm{Al}_{2} \mathrm{Si}_{2} \mathrm{O}_{5}(\mathrm{OH})_{4}\right)$, PDF 00-10-430; $A=\mathrm{Al}_{2.67} \mathrm{O}_{4}$, PDF 04-7-2478; $\mathrm{m}=\mathrm{Na}_{1.74} \mathrm{Mg}_{0.79} \mathrm{Al}_{0.15} \mathrm{Si}_{1.06} \mathrm{O}_{9}$, PDF 00-47-1498; $\mathrm{H}=\mathrm{H}_{3.64} \mathrm{Mg}_{1.48} \mathrm{Si}_{2.75} \mathrm{O}_{9}$, PDF 04-11-1215; a= anthophyllite $\left(\mathrm{Mg}_{7}\left(\mathrm{Si}_{8} \mathrm{O}_{22}(\mathrm{OH})_{2}\right)\right.$, PDF 01-75-0909; $b=$ boehmite $(\mathrm{AlO}(\mathrm{OH}))$, PDF 00-21-1307; $\mathrm{h}=\mathrm{NaH}_{3} \mathrm{SiO}_{4}$, PDF 00-16-553; +=EuAlO 3 , PDF 04-065193; $\mathrm{E}=\mathrm{EuAlO}_{3}, \mathrm{PDF}$ 00-09-084; ${ }^{\wedge}=\mathrm{A}-\mathrm{Eu}_{2} \mathrm{SiO}_{4}, \mathrm{PDF}$ 01-73-1156; ${ }^{*}=\mathrm{F}-\mathrm{Eu}_{2} \mathrm{Si}_{2} \mathrm{O}_{7}, \mathrm{PDF}$ 00-23-984; and; \#= $\mathrm{E}-\mathrm{Eu}_{2} \mathrm{Si}_{2} \mathrm{O}_{7}, \mathrm{PDF}$ 00-76-726.

Fig. 9. SEM imagine and EDX spectra of Na-Mica-2: a) initial; and; b-d) after hydrothermal treatment at $150 \stackrel{\circ}{\circ}$ for 1 month.

Fig. 10. SEM imagine and EDX spectra of Na-Mica-4: a) initial; and; b-d) after hydrothermal

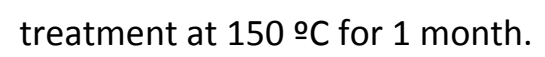



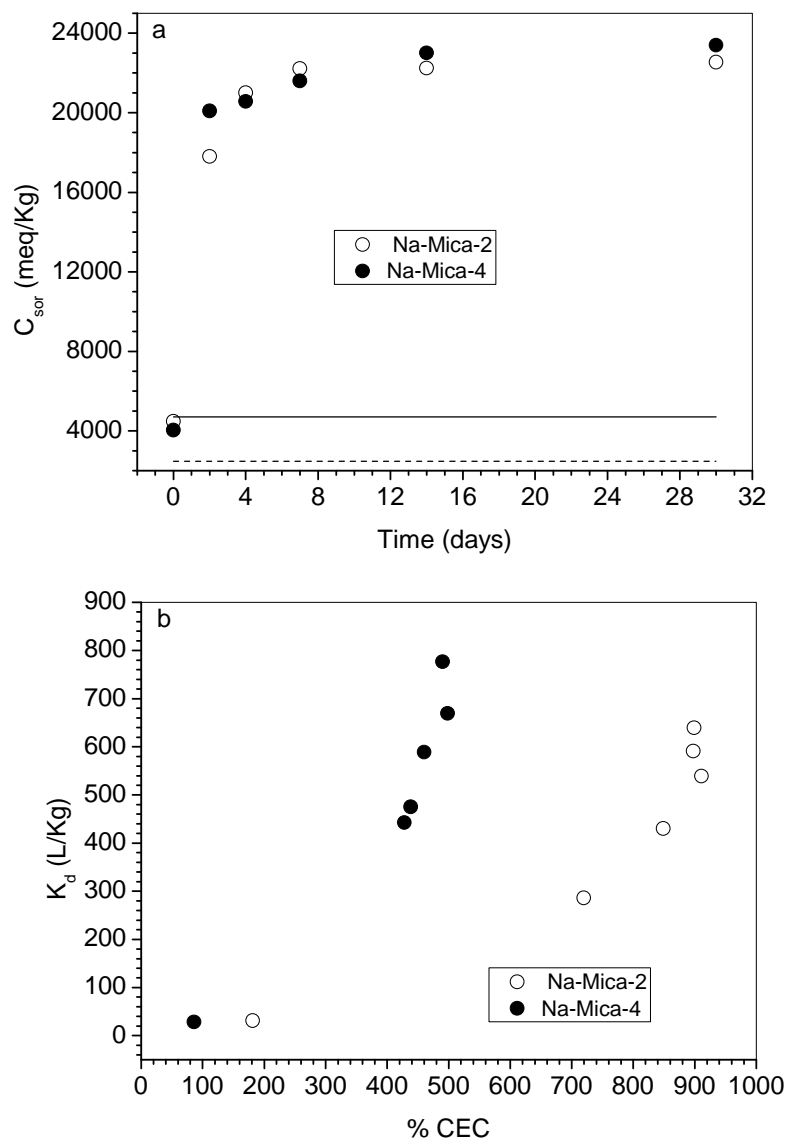

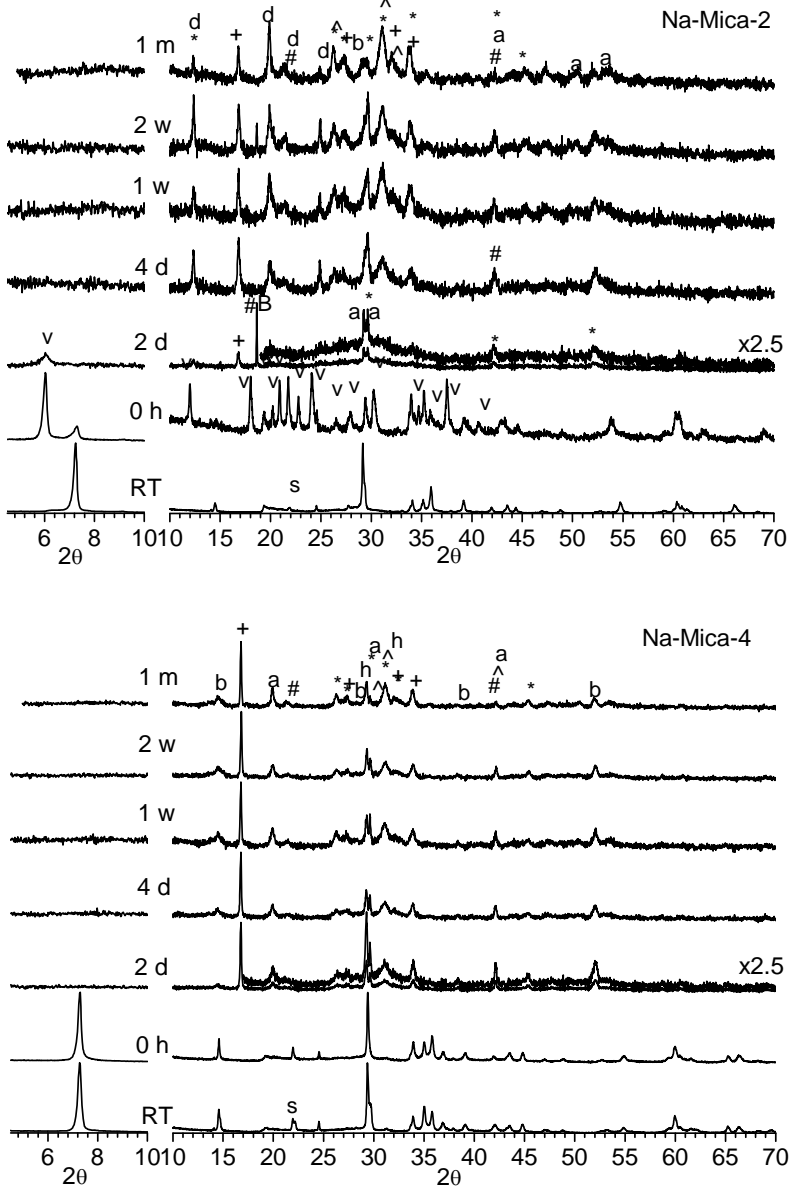
Figure 3

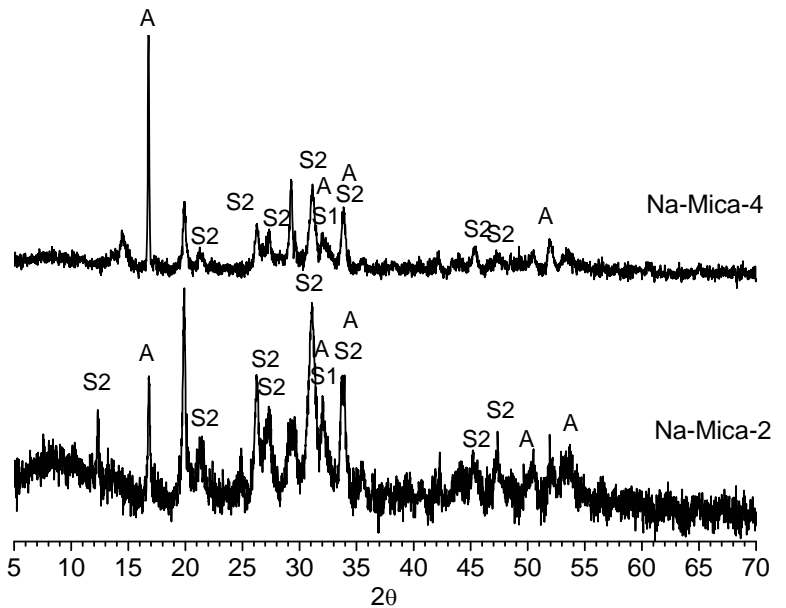



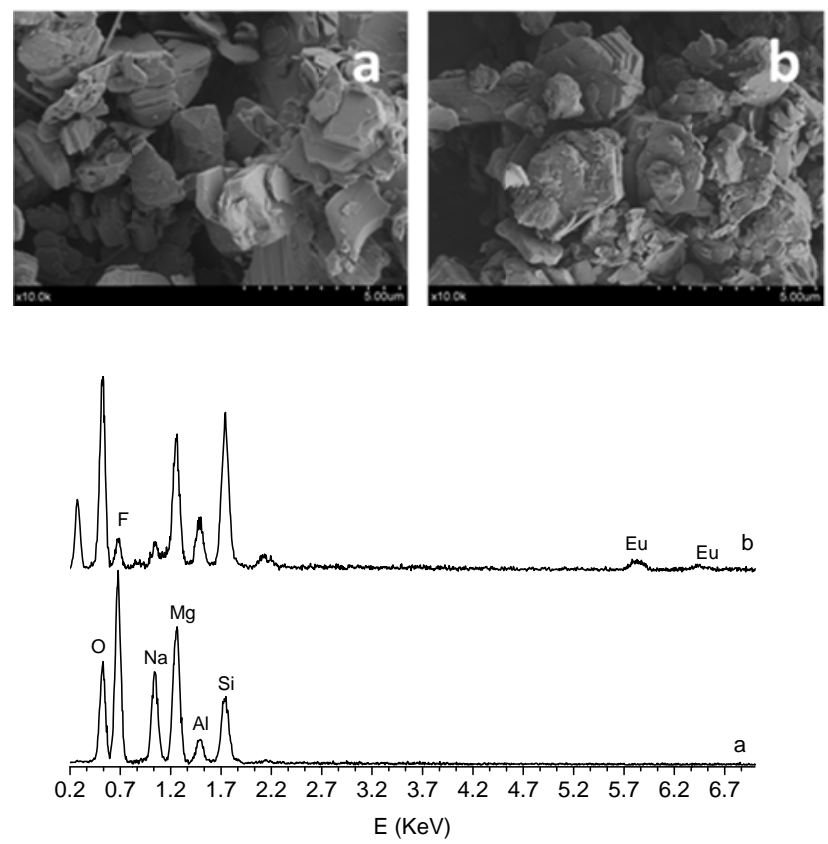

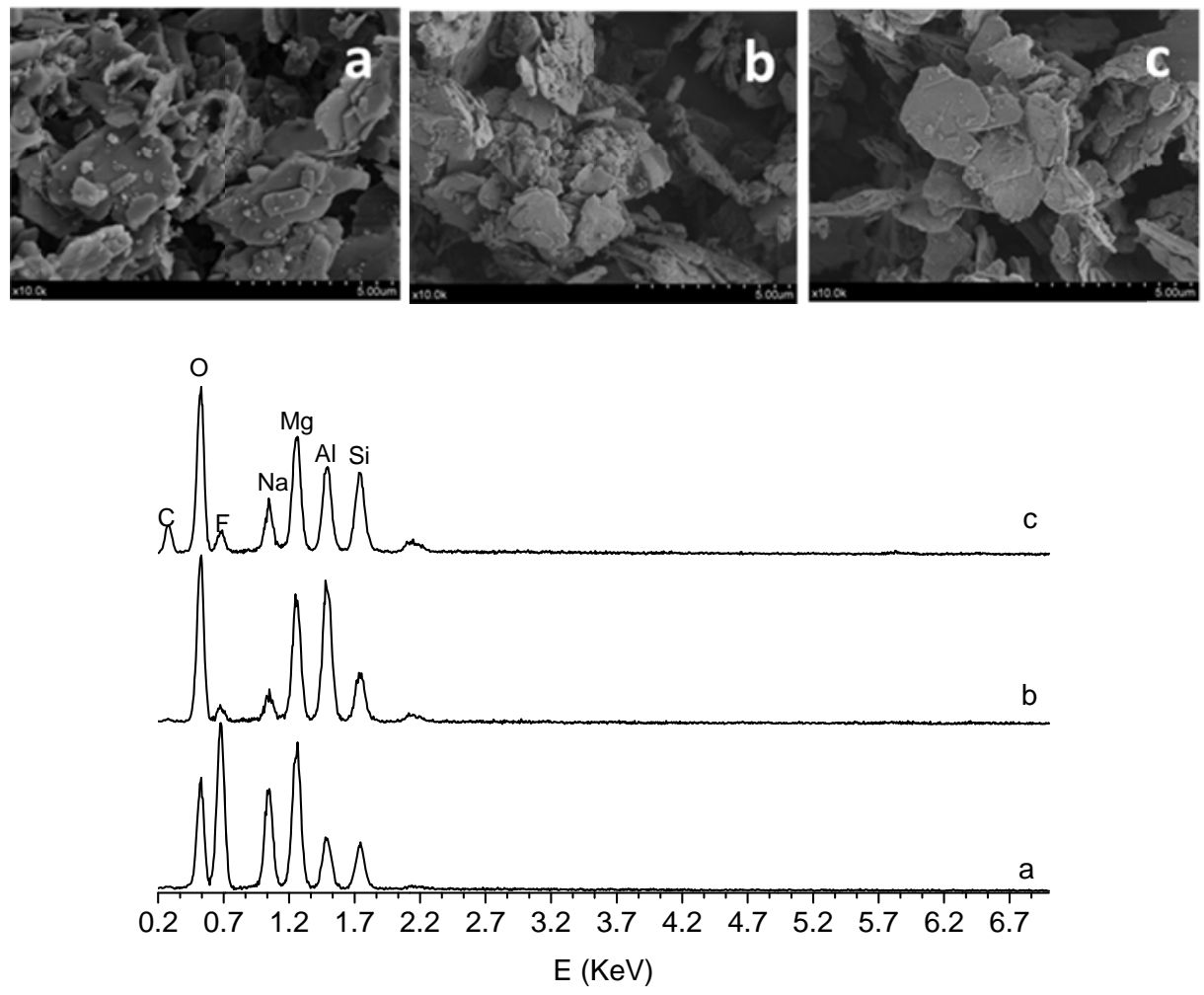

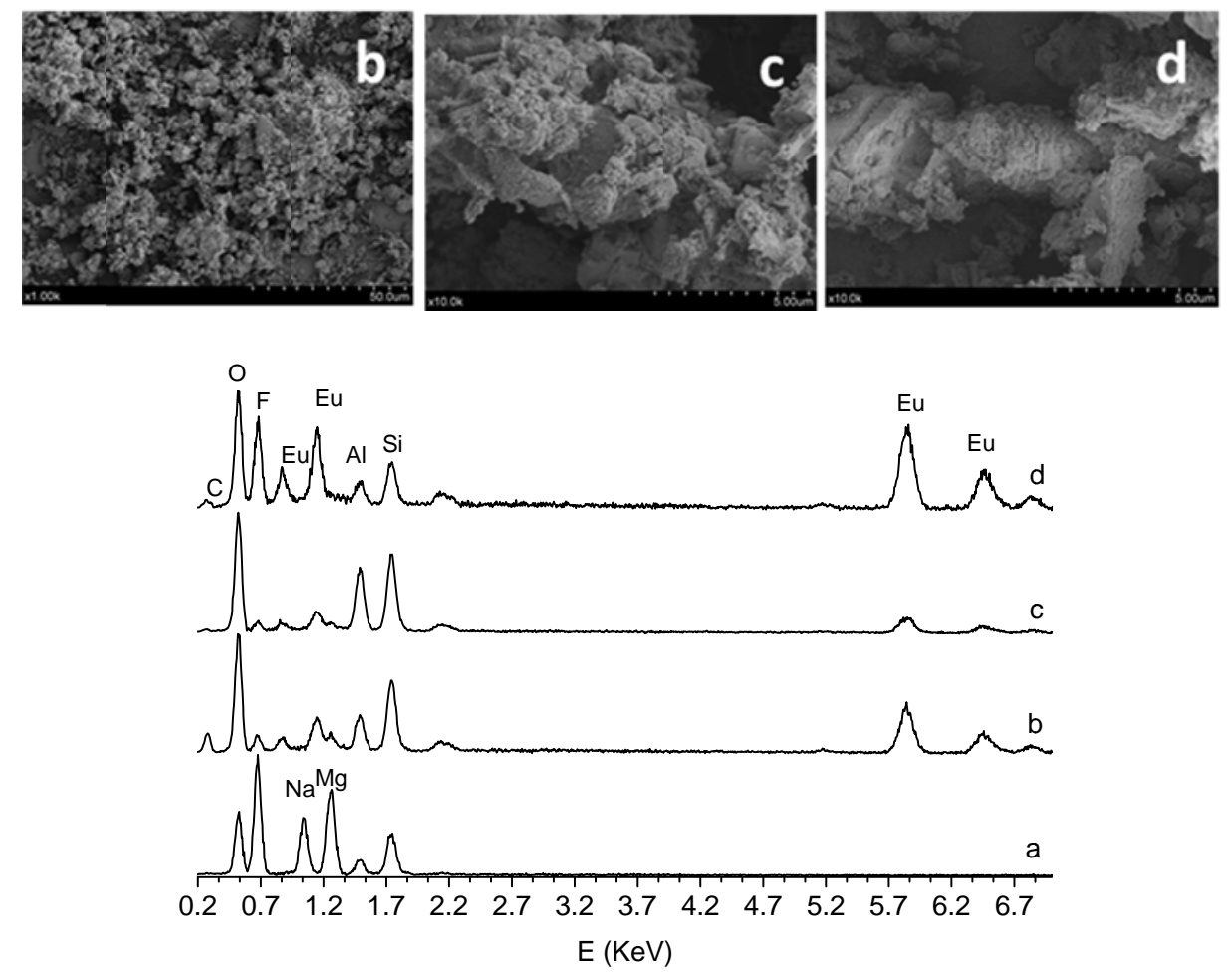

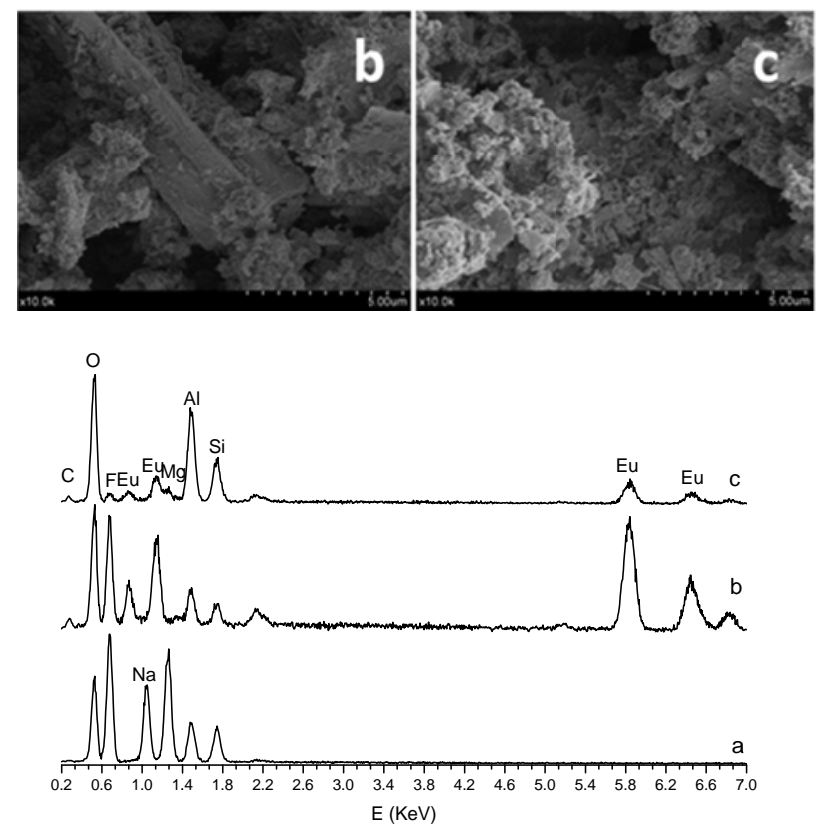
Figure 8
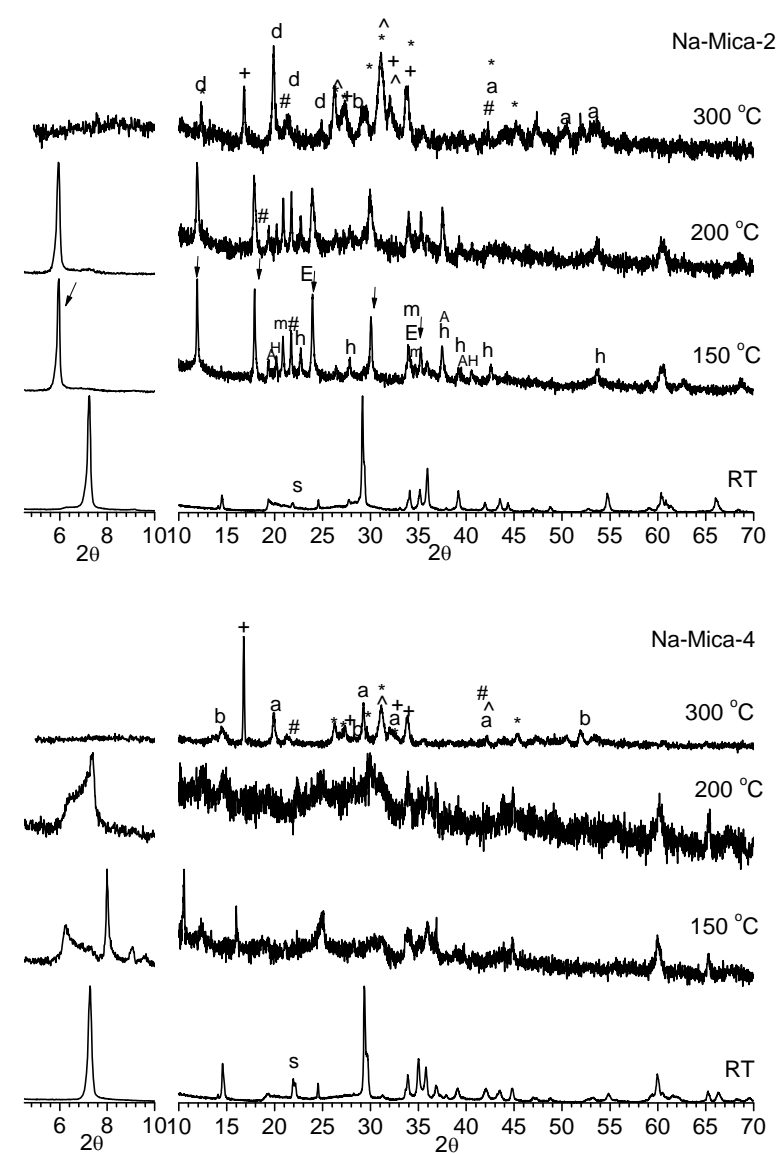

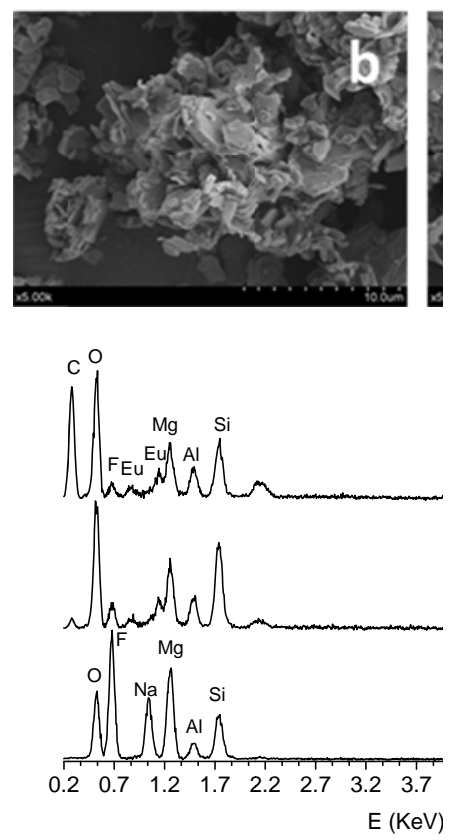